\title{
Isolated dissection of the superior mesenteric artery: rare differential diagnosis of acute abdomen
}

\author{
Niraj Nirmal Pandey, Sreenivasa Narayana Raju, Rengarajan Rajagopal, Sanjeev Kumar
}

Cardiovascular Radiology and Endovascular Interventions, All India Institute of Medical Sciences, New Delhi, India

\section{Correspondence to} Dr Sanjeev Kumar, sanjeevradio@gmail.com

Accepted 23 March 2019

\section{DESCRIPTION}

A 60-year-old man presented with a 3-day history of persistent acute abdominal pain, slightly worse after meals, not associated with nausea, vomiting, diarrhoea or haematochezia and not relieved with over-the-counter analgesics. The patient was a known hypertensive, well controlled on a singledrug regimen with no other significant relevant personal or family history.

CT angiography (CTA) revealed dissection of the superior mesenteric artery (SMA) with the dissection flap (black arrowhead) starting from distal to its ostium and extending along its entire extent (figure 1A-D). The false lumen (FL) was patent for the proximal $2 \mathrm{~cm}$ forming a cul-de-sac with near-complete thrombosis (") of the distal false lumen, causing severe compression of the true lumen (TL) (type IIB-Li classification system). ${ }^{1}$ No imaging findings suggestive of mesenteric ischaemia or any concomitant dissection of the thoracic or abdominal aorta was present. A digital subtraction angiography (DSA) confirmed the findings and showed preserved perfusion of branches arising from both the TL and FL (figure 2A). No intervention was done at the time, and the patient was managed conservatively with analgesics and bowel rest; no antiplatelet or anticoagulation therapy was initiated. However, the pain gradually worsened over a period of 10 days following which the patient was referred to our institution for possible endovascular/surgical management. A repeat DSA, however, showed disease progression with complete obliteration of the true lumen (type IIC_Li classification system) which could not be

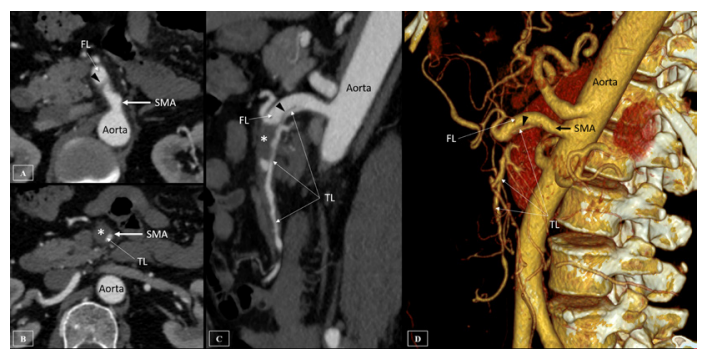

Figure 1 Axial $(A, B)$, oblique sagittal (C) maximumintensity projection images and volume-rendered images (D) of CT angiography reveal dissection of the SMA with the dissection flap (black arrowhead) starting from distal to its ostium and extending along its entire extent. The FL is patent for the proximal $2 \mathrm{~cm}$ forming a cul-de-sac with near-complete thrombosis $\left({ }^{*}\right)$ of the distal FL, causing severe compression of the TL. FL, false lumen; SMA, superior mesenteric artery; $\mathrm{TL}$, true lumen.

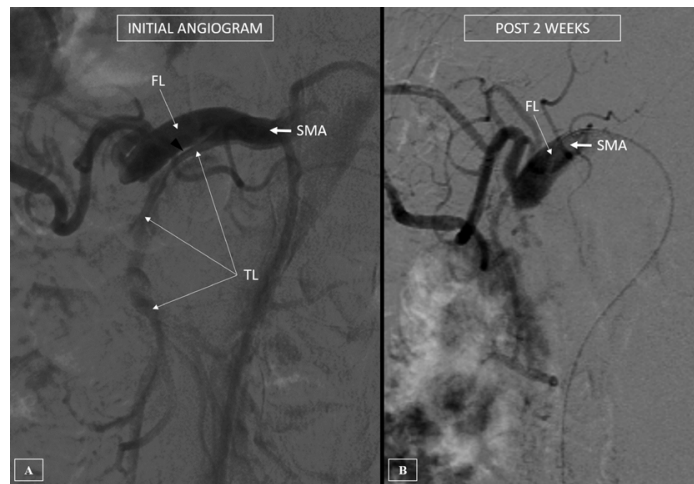

Figure 2 Initial digital subtraction angiography (A) shows a dissection flap within the SMA with the FL forming a cul-de-sac. Severe compression of the TL is noted. Digital subtraction angiography 2 weeks later shows complete obliteration of the true lumen. $\mathrm{FL}$, false lumen; SMA, superior mesenteric artery; $\mathrm{TL}$, true lumen.

crossed, even on multiple attempts (figure 2B). ${ }^{1}$ In view of persistent symptoms with failed endovascular management, the patient was advised surgical revascularisation; however, the patient refused surgery and is currently on conservative medical management.

Isolated SMA dissection without aortic dissection is rare although important differential of acute abdomen. It is associated with a wide-ranging gamut of clinical presentations, ranging from asymptomatic incidental findings to acute catastrophic bowel ischaemia/infarction or aneurysmal SMA rupture, thus posing a considerable diagnostic dilemma. $^{2}$ Cross-sectional imaging, especially CTA can establish the diagnosis unequivocally as well as detect any bowel or vessel-related complications. ${ }^{2}$ Given the rarity of the condition, its natural course and the optimal treatment strategy remains controversial. Four approaches including conservative management, anticoagulation, endovascular stenting and surgical revascularisation have been previously reported. ${ }^{2}$ Patients with asymptomatic isolated SMA dissection as well as symptomatic patients without signs of acute bowel ischaemia should undergo initial conservative management consisting of bowel rest, intravenous fluids, nutritional support and blood pressure control with or without antithrombotic therapy. Patients with persistent symptoms not relieved by conservative management for 7 days or more or with signs and symptoms suggestive of acute bowel ischaemia should undergo some intervention, either endovascular or surgical. The principal treatment objectives in isolated SMA dissection include limiting the 
extension of dissection, preserving the distal blood flow through the TL and preventing SMA rupture, all of which can be achieved by the thrombosis and obliteration of the FL. ${ }^{2}$ Taking this into consideration, the role of anticoagulation has remained controversial. Endovascular management may be indicated in cases with severe compression of TL, aneurysmal dilation of SMA $(>2 \mathrm{~cm}$ on initial scan) likely to rupture or increasing size of aneurysmal

\section{Learning points}

- Isolated superior mesenteric artery (SMA) dissection without aortic dissection is very rare; hence, the natural course and the optimal treatment strategy of this condition remains controversial.

- Principal treatment objectives include limiting the extension of dissection, preserving the distal blood flow through the true lumen and preventing SMA rupture, all of which can be achieved by the thrombosis and obliteration of the false lumen.

- Endovascular stenting of the SMA in such cases may prove sufficient for compressing the dissection flap, thereby opening the stenotic true lumen, increasing inflow and causing false lumen thrombosis, with surgical revascularisation usually limited to cases with intestinal necrosis, arterial rupture or failed endovascular management. dilation on follow-up scans and in cases with failed conservative treatment. In non-complicated cases, a bare metal self-expanding stent may prove sufficient for compressing the dissection flap thereby opening the stenotic TL, increasing inflow and causing FL thrombosis. Surgical revascularisation is usually reserved to cases with intestinal necrosis, arterial rupture or failed endovascular management and options include thrombectomy, intimectomy, patch angioplasty or aortomesenteric bypass. ${ }^{3}$

Contributors All authors participated sufficiently in the conception of the idea development of the intellectual content, design, writing and final approval of the manuscript.

Funding The authors have not declared a specific grant for this research from any funding agency in the public, commercial or not-for-profit sectors.

Competing interests None declared.

Patient consent for publication Obtained.

Provenance and peer review Not commissioned; externally peer reviewed.

\section{REFERENCES}

1 Li DL, He YY, Alkalei AM, et al. Management strategy for spontaneous isolated dissection of the superior mesenteric artery based on morphologic classification. J Vasc Surg 2014;59:165-72.

2 Min SI, Yoon KC, Min SK, et al. Current strategy for the treatment of symptomatic spontaneous isolated dissection of superior mesenteric artery. J Vasc Surg 2011:54:461-6.

3 Park YJ, Park KB, Kim DI, et al. Natural history of spontaneous isolated superior mesenteric artery dissection derived from follow-up after conservative treatment. J Vasc Surg 2011;54:1727-33.

Copyright 2019 BMJ Publishing Group. All rights reserved. For permission to reuse any of this content visit

https://www.bmj.com/company/products-services/rights-and-licensing/permissions/

BMJ Case Report Fellows may re-use this article for personal use and teaching without any further permission.

Become a Fellow of BMJ Case Reports today and you can:

- Submit as many cases as you like

- Enjoy fast sympathetic peer review and rapid publication of accepted articles

- Access all the published articles

Re-use any of the published material for personal use and teaching without further permission

For information on Institutional Fellowships contact consortiasales@bmjgroup.com

Visit casereports.bmj.com for more articles like this and to become a Fellow 